\title{
TEORIA DA LEITURA COMO CONTATO CULTURAL: DESLOCAMENTOS, VIAGENS E ALTERIDADE NO ATO DA LEITURA DE FICÇÕES
}

\author{
THEORY OF READING AS CULTURAL CONTACT: \\ DISPLACEMENT, TRAVEL AND OTHERNESS IN THE ACT OF READING FICTION
}

Luiz Antonio Silva*

\begin{abstract}
Resumo: 0 presente artigo consiste numa análise dos pressupostos e contribuições da Teoria da leitura como contato cultural, criada por Gabriel Schwab, professora da Universidade da Califórnia, nos anos 90. Essa teoria defende o principio de que a leitura de textos literários permite uma espécie de negociação entre os limites culturais dos leitores e dos textos, assim, ler representa uma espécie de contato cultural. Ao mesmo tempo, percebe se que essa teoria é configurada a partir de um diálogo interdisciplinar entre as Teorias da Recepção e os Estudos Culturais, aspecto também analisado no presente estudo. Palavras-chave: Teorias da recepção; contato cultural; Estudos culturais e textos literários.
\end{abstract}

\begin{abstract}
This article is an analysis of the framework and contributions of the theories of reading as cultural contact created by Gabriele Schwab, professor at the University of California in the 90s. This theory advocates the principle that the reading of literary texts allows a kind of negotiation between cultural limits of readers texts, thus reading it represents a kind of cultural contact. Thus, this theory is configured from an interdisciplinary dialogue between Reader Response Critiscm and Cultural Studies, aspect also analyzed in this study.
\end{abstract}

Keywords: Reader response criticism; Cultural contacts; Cultural Studies and Literary texts.

A teoria da leitura como contato cultural foi desenvolvida nos anos 90 por Gabriele Schwab, professora da University of California-Irvine, e representa uma profunda mudança nas teorias da recepção, pois esse estudo consiste num tipo de reflexão sobre as dimensões psicológicas, culturais e políticas do ato da leitura -- aquelas que estão ligadas às operações de transferência e de contato cultural. Pode-se afirmar que essa

\footnotetext{
* Professor Substituto no Departamento de Literatura Brasileira e Teoria da Literatura da UERJ, pósdoutor (recém-doutor) em Teoria da Literatura. Doutor(2007) e mestre(2002) em Estudos de Literatura na PUC-Rio . Foi pesquisador visitante na Brown University (2001 e 2006). Tem graduação em História pela UERJ(1998). E-mail para contato: lasilva1974@gmail.com.
} 
teoria busca estabelecer um diálogo entre as Teorias da Recepção e os Estudos Culturais. Dessa maneira, o presente artigo tem como objetivo: identificar e examinar os pressupostos teóricos, epistemológicos, filosóficos e políticos da Teoria da leitura como contato cultural, destacando como essa teoria foi construída a partir da união das Teorias da Recepção e com os Estudos Culturais e sua relevância para contemporaneidade.

Portanto, a importância deste trabalho está na possibilidade de explorar a transgressão de limites teóricos combatível com as demandas que a nossa contemporaneidade, radicalmente multicultural, impõe às ciências humanas e sociais. Assim, essa reflexão é relevante, nesse contexto, em que a experiência literária perde espaço com a expansão do áudio-visual e, ao mesmo tempo, a necessidade por desenvolver novas formas de relação com alteridade passa a ser fundamental, visto a paradoxal propagação da intolerância e do fundamentalismo em sociedades multiculturais.

Para tal concepção teórica, o ato de ler é considerado uma operação de limites que possibilita negociações entre fronteiras marcadas por diferenças históricas, culturais e estéticas. Para fundamentar esse princípio, Gabriele Schwab (SCHWAB, 1996) procura definir como a alteridade e o contato cultural, operam na produção e, especialmente, na recepção literária. O contato cultural é considerado, conforme a perspectiva de Gregory Bateson (BATESON, 1972, p. 61-72) não apenas enquanto contato entre duas ou mais comunidades com culturas diferentes, mas também nas situações em que o contato ocorre dentro de uma mesma comunidade.

A partir dessa perspectiva, percebe se como uma forma de contato cultural, a relação que a literatura estabelece entre seus leitores e a cultura na qual um texto literário é produzido e interage. Isso pode ser ampliado não só para os nossos hábitos individuais de leitura, como também para os processos em que somos socializados a partir dos nossos hábitos de leitura. A teoria liga a função cultural da literatura ao seu poder de nos afetar e de mudar e interferir nas práticas culturais. Entretanto, tais mudanças e interferências são frequentemente provocadas por encontros com a alteridade que desafia suposições familiares, abrindo novas perspectivas, não só em relação ao texto, como também, em relação à realidade extra textual. 
Literature, in other words, affects us most when it displays a resonating otherness or unfamiliar, if not uncanny, resonance. Aesthetic categories such as "innovation" or "defamiliarization" grasp the structural and aesthetic aspect of this phenomenon. (SCHWAB, 1996, p.10).

Tal como outras formas de contato cultural, a leitura afeta as referências culturais tanto de leitores individuais, como de comunidades interpretativas, porque, ao atuarem como agentes de contatos culturais, as obras literárias interferem nos limites de suas próprias Culturas. Por outro lado, os textos também configuram várias formas de socialização numa mesma cultura. Sendo assim, essas alterações de limites são determinadas pela história da leitura, de comunidades culturais e também de leitores individuais.

Segundo essa linha de pensamento, é possível entender os padrões culturais de relacionamento com a alteridade, como um assunto pedagógico, no qual percebemos a existência de uma espécie de educação cultural que pode ser desenvolvida através da mudança de tipos históricos de atos da leitura. Em tal educação, as posturas etnocêntricas ou egocêntricas são transformadas a partir da transgressão de seus limites, que a recepção da alteridade do texto literário proporciona. Isso se amplia para a própria questão da construção do conhecimento, pois a experiência literária torna-se um espaço, no qual, posturas etnocêntricas, sexistas e racistas são desafiadas. Ou seja, essa teoria apresenta também uma abordagem epistemológica sobre os estudos literários.

De um modo geral, Schwab chama atenção para o fato de que, no contexto contemporâneo, altamente tecnologizado e globalizado, existe a nítida troca de uma cultura literária por uma cultura visual, configurada na redução do espaço público e da atenção destinados à literatura. Entretanto, a literatura tem desenvolvido formas experimentais que afetam profundamente o ato da leitura. Consequentemente, nessas experiências literárias, inauguram-se contatos culturais diferentes daqueles que são promovidos nas práticas culturais estruturadas pela mídia de massa e pelas novas tecnologias da informação. Tais experiências são criadas a partir do uso das diferentes formas de alteridade literária, histórica e cultural que encontramos, por exemplo, desde o alto modernismo até o pós-modernismo.

Outro aspecto importante que a teoria da leitura como contato cultural dá destaque, diz respeito às relações de poder que resultam em imposições de sentidos aos textos, nos contatos culturais estabelecidos entre leitores e textos de diferentes culturas 
ou entre leitores e textos de uma mesma comunidade cultural. Gabriele Schwab ilustra muito bem a questão das relações de poder na imposição de significados, ou na repressão a interpretações, quando analisou o famoso artigo de Laura Bohannan (BOHANNAN, 1966, p.28-33), uma antropóloga norte americana, chamado Shakespeare in the bush. Tal artigo é um relato de experiência que antropóloga passou nos anos sessenta, após uma discussão com um acadêmico inglês sobre a universalidade da obra de Shakespeare, e decidiu fazer uma experiência de ler Hamlet para nativos numa tribo do norte da África, chamada Tiv.

No início dos anos sessenta, Laura Bohannan estava na Universidade de Oxford e, num certo dia, um amigo britânico da mesma universidade disse a ela que os americanos frequentemente têm dificuldades com as peças de Shakespeare, porque, antes de qualquer coisa, Shakespeare é um poeta inglês e qualquer um pode interpretar erroneamente o universal pela falta de entendimento do particular. Ela respondeu em protesto, afirmando que aquilo estava errado, pois a natureza humana é quase a mesma em todo o mundo, assim, a essência das grandes tragédias seria sempre clara em qualquer lugar. Por essa razão, Bohannan resolve ler a peça Hamlet para os nativos que visitou no norte da África, após essa temporada em Oxford, os Tiv. A experiência de leitura de Hamlet com os Tiv foi, então, realizada para provar a universalidade da obra de Shakespeare.

Entretanto, o contato dos Tiv com a narração de Hamlet, feita pela antropóloga, criou uma inusitada situação, na qual códigos culturais e pressupostos sobre interpretação, poder e hierarquia entre culturas e pessoas, entram em jogo a partir de práticas interpretativas. Para os Tiv, o ato de contar histórias é uma arte refinada e muito importante para sua vida social, pois todas as histórias contadas guardam um específico sentido verdadeiro. Dessa maneira, os anciãos são os que têm o poder de determinar o verdadeiro sentido das histórias, eventos, situações, ações e fenômenos da natureza.

Isso explica a reação que os anciãos dos Tiv tiveram ao ouvir a versão de Hamlet narrada pela antropóloga. Ela inicia a narração contando que, há muito tempo, uma coisa aconteceu: numa noite, três homens, que estavam vigiando o domicílio do grande chefe do povo deles, subitamente viram o chefe anterior se aproximar. Um dos anciãos perguntou por que esse homem, visto pelos vigilantes, não era mais o chefe e a 
antropóloga respondeu, dizendo que ele estava morto e que isso fez com que os vigilantes ficassem com medo. Um outro ancião argumentou, assustado, que seria impossível que aquela pessoa fosse o chefe morto, deveria ser um agouro de uma bruxa. Laura Bohannan continuou sua apresentação do enredo da peça de Shakespeare, dizendo como o príncipe Hamlet, filho do chefe morto, ficou muito contrariado, porque seu tio Claudius tornou-se o chefe e também se casou com a viúva de seu irmão mais velho, apenas um mês depois do funeral. Para surpresa da antropóloga, um ancião afirmou que Claudius estava certo ao se casar com a mãe de Hamlet e que, se ele soubesse mais sobre os europeus, poderia realmente considerá-los semelhantes aos Tiv, pois, segundo a convenção social dos Tiv, o irmão mais novo deve-se casar com a viúva do seu irmão mais velho e se tornar o pai de suas crianças.

Mais surpreendente ainda, foi a conclusão que os anciãos elaboraram sobre toda a história, na qual classificaram Hamlet como um vilão, pois xingou a sua mãe, matou Polonius e se rebelou contra o seu tio Claudius, que, conforme o esperado, casou-se com sua mãe e substituiu seu pai no reinado. E, assim, um dos anciãos se ofereceu, em nome de todos os demais, para ensinar à antropóloga o verdadeiro sentido das estórias que ela contava.

Por seu lado, Gabriele Schwab observa que Laura Bohannan, ao apresentar as reações e interpretações dos anciãos, estabeleceu um pacto com os leitores ocidentais para estigmatizar a leitura dessas autoridades tribais como infantis, fora de lugar e delirantes. Em suma, através desse exemplo, Gabriele Schwab demonstra como a questão da repressão sobre interpretações está ligada aos valores e regras sociais, e às relações de poder estabelecidas entre culturas e até entre grupos sociais de uma mesma cultura. Ao mesmo tempo, a forma de narrar e de interagir com a alteridade, manifestada no ato da leitura de outras pessoas ou de outra cultura, também é configurada a partir das relações de poder que compartilham diferentes grupos sociais. No caso das estratégias retóricas, usadas pela antropóloga, essas representam o olhar colonizador dos ocidentais em relação a uma tribo africana, pois a forma usada pela antropóloga de contar a história de Hamlet foi muito semelhante às versões infantilizadas de contar os clássicos da literatura para as crianças.

No plano dos pressupostos teóricos, Gabriele Schwab apresenta as correntes teóricas e filosóficas que estruturam a sua ideia da leitura como contato cultural. 
Justamente nesse ponto da sua reflexão que podemos entender a sua relação com as Teorias da Recepção. Inicialmente Schwab crítica a corrente hermenêutica através do modelo dialógico de Hans-Georg Gadamer (GADAMER, 1999) e sua apropriação pela estética da recepção de Hans Robert Jauss, uma das mais importante representantes das Teorias da Recepção. Para a autora, no conceito de interpretação, baseado num modelo dialógico oriundo da hermenêutica de Hans-Georg Gadamer, existe a apropriação da alteridade cultural apenas dentro da sua própria tradição cultural, ou seja, considera-se apenas a alteridade histórica na tradição cultural ocidental.

Para Gadamer, o termo "interpretação" significa o papel de tradutor e mediador entre as linguagens de diferentes culturas. Interpretação neste sentido, é uma modalidade antropológica do ser que forma uma mediação que nunca foi completamente estabelecida entre seres humanos e o mundo. Sendo assim, os textos servem como objetos intermediários, em tal mediação. Schwab continua a descrição afirmando que, sendo interativa e dialógica, a teoria da interpretação de Gadamer não considera o significado de textos literários como fixo, mas sim, criado pelos leitores, cuja atividade media o "horizonte" de um texto - sua alteridade histórica ou linguística com os seus próprios horizontes.

É deste ponto da teoria de Gadamer, que Hans Robert Jauss (JAUSS, 1994) desenvolve a sua teoria da recepção literária, na qual é argumentado, que os leitores realizam uma fusão de horizontes para receber historicamente textos literários remotos. De acordo com essa perspectiva, um evento estético apenas ocorre, quando um texto resiste a tal fusão e nega confirmar as expectativas e pré-concepções dos leitores. Desta forma, tanto para Gadamer quanto para Jauss, a recepção de uma obra literária é uma experiência de alteridade. Porém essa alteridade não é dada e nem pode ser encontrada num texto, mas surge apenas como um efeito de expectativas frustradas a respeito de normas estéticas, gostos e preconceitos culturais procedentes das próprias tradições e da historia dos leitores. Alteridade não é, nessa visão, propriedade dos textos, mas é criada na produção do significado. Como as obras passam de um contexto cultural e histórico para outro, seu significado e sua relação com a alteridade mudam correspondentemente, porque serão recriadas dentro de novos horizontes de expectativa. 
Essa visão ignora o caráter violento que apropriações interculturais estabelecem. Sendo assim, preconceitos raciais, culturais, sexuais que, segundo Schwab, podem determinar a interpretação de obras literárias, não entram no horizonte de Gadamer. Ou seja, as formas de contato cultural estabelecidas entre as nações européias e outras culturais formadas em outros continentes nos processos de colonização e imperialismo. Por outro lado, Gabriele Schwab ampliou alguns conceitos da teoria do efeito estético de Wolfgang Iser, uma outra teoria das teorias da recepção, desviando-se em direção ao estudo das dimensões psicológicas, culturais e políticas do ato da leitura -- aquelas que estão ligadas às operações de transferência e de contato cultural. Isso porque, segundo o seu ponto de vista, enquanto a Gadermer e Jauss estruturaram as suas teorias da recepção literária num modelo interpessoal, o conceito de Wolfgang Iser de leitor implícito, contrariamente enfatiza a dimensão comunicativa inerente aos próprios textos. O leitor implícito de Iser (ISER, 1996) não se refere a um leitor individual e empírico, mas sim às estratégias de comunicação do texto, que exerce um certo controle, por convidar ou privilegiar, respostas específicas. O leitor implícito é uma ação textual que ativamente, confirma, interfere e rompe com um padrão de comunicação de uma cultura que está presumidamente internalizado por seu leitor. Desta forma, Iser se preocupou com o aspecto interativo da leitura em detrimento da tentativa de compreender a ação de leitores individuais, cujas respostas nunca poderão ser verificadas face a face.

No entanto, Schwab nos lembra, que a metáfora da interação refere-se a ações textuais que guiam a recepção de leitores que ativamente "processam" o texto. Ou seja, a autora nos mostra que para Iser a interação texto e leitor se refere a um leitor individual, onde começa a transferência de sentido que somente será bem sucedida se o texto conseguir ativar certas disposições da consciência do leitor - a capacidade de apreensão e de processamento.

A concepção da leitura como contato cultural consiste, em parte, numa alteração de alguns conceitos de Iser, principalmente por considerar os modos histórico e psicológico de processar os textos concretos, incluindo os modos do inconsciente. Processar o texto, para Schwab, é muito mais que uma transferência neutra, é uma transferência pesadamente investida entre leitor e texto, que pode ser entendida, como um processo no qual a formação psicológica e cultural da alteridade é trazida para o 
jogo. A noção de transferência permite também que se perceba o texto literário como uma ação que convida a uma certa interação ou, mais precisamente, uma certa projeção controlada. Assim, os textos são vistos como ações ativas que produzem certos efeitos subjetivos em seus receptores, possibilitando, então, uma forma de contato cultural que transforma ambos em agentes envolvidos.

Em suma, percebemos que a teoria de Schwab corresponde a uma inversão daquilo que consiste o pensamento de Wolfgang Iser sobre efeito e também produção de textos literários. Ou seja, enquanto Iser está preocupado em apresentar o caráter neutro da experiência literária como um espaço performativo no qual podemos nos desligar das limitações culturais e históricas em que estamos inseridos, Gabriele Schwab procura demonstrar como, nossas bagagens culturais e históricas, são trabalhadas e negociadas com outras formas culturais através da leitura e da escrita de textos literários.

Esse deslocamento teórico do ponto principal da obra de Iser é muito bem apresentado na conferência, que Gabriele Schwab (SCHWAB, 1999) proferiu no VII Colóquio da UERJ, intitulada, 'Se ao menos eu não tivesse de manifestar-me': a estética da negatividade de Wolgang Iser" na qual são analisadas as questões fundamentais das diferentes fases da obra de Iser, partindo da teoria do efeito estético até a antropologia literária. Nessa comunicação, Schwab, destaca a contribuição da obra de Iser aos estudos literários atuais e, principalmente, mostra como a teoria da leitura como contato cultural, que ela propõe, foi influenciada por essa visão teórica.

A pergunta referente à necessidade humana de ficções, segundo Schwab, motivou a criação da teoria de efeito estético, como também a antropologia literária, propostas por Iser. Além disso, a autora nos adverte de que as tentativas de responder essa pergunta significaram a legitimação dos estudos de literatura. Tal legitimação foi muito importante, tanto no contexto dos anos sessenta e setenta, quando o reader-response criticism surgiu, quanto é para os dias atuais. Isso porque, hoje, percebemos, de um lado, a perda de espaço do discurso ficcional para a cultura midiática e, de outro, o surgimento de uma nova tendência antropológica dos estudos de literatura, uma tendência que se instalou com o advento do novo paradigma cultural e sua ampliação nas disciplinas das ciências humanas.

A outra questão fundamental da obra de Wolfgang Iser é representada pela condição que, segundo Schwab, Samuel Beckett formulou na seguinte frase: "Se ao 
menos eu não tivesse de manifestar-me". Isso consiste no desejo, percebido nas entrelinhas iserianas, de escapar de qualquer determinação que estabeleça seus pressupostos epistemológicos e sua posição política. Além disso, a negatividade, representada por essa condição, é tema dos estudos de Iser, e simultaneamente, o principal elemento que estrutura toda sua obra.

Gabriele Schwab nos explica como a leitura, na concepção de Iser, é entendida em termos de transferência, processamento, mediação ou tradução, na qual a interação entre leitor e texto, é apoiada na negatividade e na indeterminação, como formas de contato. Porém, a indeterminação e a negatividade também estão presentes na construção do texto literário, e assim, a determinação é excluída, tanto da leitura quanto da criação literária, na perspectiva de Iser. Em suma, é muito claro que esse modelo teórico mantém a literatura e até as suas premissas epistemológicas, numa espécie de abstração, na qual questões de ordem histórica, psicológica ou cultural não estão envolvidas.

Voltando à pergunta sobre a necessidade humana de ficção, a autora afirma que Iser não responde a essa questão, dizendo que precisamos moldar a nós mesmos e também ao nosso mundo. Ao contrário, argumenta que, ao nos "duplicarmos" através da ficção, estamos "desfazendo" a nós mesmos na tentativa de escapar da prisão em que nos confinam as determinações culturais, históricas e psicológicas.

Em termos teóricos, essa mudança pode ser representada pela inclusão do conceito de "encenação". A noção de encenação, em Iser, complementa o ato da leitura e é o que permite atos performativos nos quais indivíduos e até culturas duplicam a si mesmos. É justamente nesse ato que os seres humanos conseguem encenar a diferença existente entre "ser quem são" e "ter a si mesmos". Considerando que o "ter a si mesmo" significa autoconhecimento, então, Iser argumenta que existe uma alteridade intrínseca nos seres humanos que provoca o desejo de auto-representação e auto-exploração, e é esse tal desejo que origina a necessidade de ficção.

Gabriele Schwab conclui sua análise afirmando que, na visão iseriana, a literatura não é um simples complemento ou compensação, mas é o que nos propicia entrar em contato com algo que não conseguimos vivenciar ou conhecer de maneira consciente. Segundo a autora, essa é a perspectiva que mais influenciou a sua própria teoria, teoria na qual a leitura é entendida como uma forma de contato cultural. 
No enfoque da leitura como contato cultural, Schwab constrói uma nova visão teórica e metodológica a partir do questionamento da inexistência de um papel cultural na noção iseriana de alteridade intrínseca, com que entramos em contato por intermédio da literatura. A base dessa teoria é claramente apresentada na pergunta que Gabriele Schwab fez diretamente para Iser: "De que forma a alteridade intrínseca aos seres humanos está relacionada ao ou é constituída pelo outro, seja um outro ser humano, seja um Outro cultural, seja uma alteridade simbólica?" (SCHWAB, 1999, p. 44).

Sendo assim, a autora se prende especialmente à noção iseriana de transferência, entretanto trabalha uma noção de transferência que requer uma base psicológica, cultural e social. Aqui, a transferência do texto ao leitor é concebida como um processo que opera coletiva e individualmente; tal base deve ser desenhada numa psicologia cultural.

Nesse ponto que o pensamento de Gabriele Schwab sai do universo das teorias da recepção, construídas a partir da hermenêutica e especialmente da fenomenologia e da antropologia literária iserianas, para construir diálogos com correntes da sociologia, da psicanálise e dos Estudos Culturais, para compor a idéia de contato cultural pela recepção literária.

Essa trajetória começa quando ela usa determinados conceitos de Mikhail Bakhtin. Para Bakhtin, nós não podemos ser nós mesmos sem o outro e, assim, só devemos nos encontrar, de fato, no outro. Além disso, somos informados por Schwab de que, nos estudos de Bakhtin, a teoria da linguagem é inseparável de uma psicologia na qual o psicológico, o corporal e a linguagem, formam uma unidade inseparável. A premissa básica da antropologia filosófica de Bakhtin, consiste no que ele chama de absoluta necessidade estética do outro.

Segundo a argumentação de Schwab, na psicologia cultural de Bakhtin o olhar não é um meio de alienação, conforme a concepção de Lacan, de que na fase do espelho, o sujeito sucumbe narcisicamente à ilusão de unidade, mas é sim, um meio de realização. Bakhtin insiste num "vazio" perceptual e emocional da experiência do espelho que se dirige à carência do outro. Isso faz com que a visão de Bakhtin seja contrária às de Lacan e de Sartre. Para o primeiro, existe uma reciprocidade fatal entre formação do sujeito e o olhar do outro e, para, o segundo, existe uma pseudo-singularidade, que se tenta 
preservar nas espirais infinitamente regressivas que se formam na interação de dois olhares subjetivos e autoconscientes. Isso porque Bakhtin percebeu um mútuo olhar de sujeitos que encontram a si mesmos no exterior, no outro ou no limite do outro, destacando que a tentativa de se escapar do outro, significa perder a si mesmo.

Seguindo essa linha de pensamento, a autora faz uma aproximação dessa concepção de olhar o outro em Bakhtin, resumida na expressão "encontrar a si mesmo no lado de fora", com o que Todorov chamou de exotropia. Aqui é reconhecido que, ao aceitarmos os padrões de acordo com os quais uma cultura constrói a alteridade, estamos ligados a sua formação sócio e psicogenética de sujeitos em relação ao outro. Não só a antropologia de Bakhtin, mas também a sua estética estão sobre a base de uma teoria psicológica do cultural. Exotropia é entendida aqui como o modo básico da produção e principalmente da recepção artística, pois a leitura é vista enquanto vinculada com o olhar do leitor que absorve o texto numa tensão de semelhança e diferença, na qual esse encontra a si mesmo no limite de transformar o outro, em um "eu-outro" (self-other).

No contexto destas reflexões de Bakhtin, existe uma especial preocupação com a questão da história coletiva e individual da leitura. É justamente deste ponto, que Schwab parte para tratar das nossas experiências iniciais de recepção, ao ouvir e até mesmo ler histórias na infância, as quais serão preservadas pelo resto de nossas vidas como uma fonte vital de prazer. Então, segundo essa visão, nossos modelos iniciais de leitura não serão abandonados, mas serão alterados e fundidos com novos modos de leitura que adquirimos posteriormente. Diferentes modos de leitura podem ser completados ou suplementados por outros, conforme necessidades psicológicas e históricas.

Quanto mais desenvolvemos nossos hábitos de leitura, mais diferenciados, complexos e ambivalentes eles se tornam. Tal processo é semelhante ao que acontece com as crianças quando começam a perceber o mundo de fora como algo diferenciado, o mesmo acontece com o mundo ficcional e seus personagens. Na relação com o mundo ficcional, o intercâmbio com a alteridade entra em jogo; aí surgem formas não destrutivas de se lidar com o Outro e também de se distinguir-se enquanto eu. Ou seja, na interação com o mundo ficcional, os modos arquétipos de enfrentar a alteridade (rejeição e assimilação) são transgredidos; por exemplo, as crianças muitas vezes 
desenvolvem uma rejeição e, ao mesmo tempo, uma fascinação, por personagens considerados maus.

Todo esse conjunto de reflexões que envolvem a exotropia, e os arquétipos das relações com a alteridade (rejeição e assimilação) são articulados com os estudos psicanalíticos de Donald W. Winnicott, pediatra e psicanalista britânico, sobre o desenvolvimento da criança, linguagem, alteridade e arte. Para Winnicott, nas relações iniciais com a linguagem, a criança usa os sons como um objeto transitório, através dos quais ela percebe o seu próprio som como algo interno e externo, simultaneamente. Existe um "eu" e um "não eu" no ato de produzir sons, e isso, constitui um objeto transitório que antecede qualquer objeto cultural. Toda a nossa relação com literatura e com arte em geral, se torna uma espécie de retorno ao objeto transitório, formando um espaço transitório, no qual desfrutamos o prazer de retornar à experiência de sermos nós mesmos e o outro, simultaneamente. Assim, ler consiste numa experiência de contato com a alteridade interna e externa, na qual experimentamos um espaço transitório e, assim, nossos próprios limites são postos em suspensão. Enfim uma profunda experiência de contato cultural.

A partir dessa rica formulação teórica a partir de pressupostos das teorias da recepção, da sociologia de Bakhtin e Todorov e da psicanálise de Winnicott, o estudo de G. Schwab constrói uma singular conexão com os estudos culturais, ou seja, foi através dessa trajetória reflexiva que a leitura pode ser entendida a partir de conceitos e formulações dos estudos culturais, especialmente, a partir do conceito de alteridade, tema muito trabalhando por importantes correntes desse campo de conhecimento.

Os estudos culturais (ESCOSTEGUY, 1998) tiveram suas origens no Centre for Contemporary Cultural Studies (CCCS), fundando por Richard Hoggart em 1964, e ligado ao English Departament da Universidade de Birmingham na condição de programa de pós-graduação. 0 trabalho de pesquisa de Richard Hoggart, The Use of Literacy(1957), a obra de Raymond Willams Culture and Society(1958) e o livro A formação da Classe operária inglesa(1963) são os trabalhos fundadores dos Estudos Culturais.

O que unem essas três obras e a consequente formação de pontos teóricos em comum é o interesse em analisar a cultura de uma sociedade a partir dos comportamentos e práticas compartilhadas por todos seus membros que produzem e consomem textos, práticas e bens culturais. Tal perspectiva buscou transgredir as 
hierarquias entre as práticas culturais e considerar as práticas culturais como formas materiais e simbólicas, ou seja, a produção de cultura está no espaço social e econômico. Entretanto, não há um reducionismo nestas perspectivas, pois o econômico, político e cultural - competindo em conflitos entre si.

Desta forma, a cultura não pode ser reduzida também ao objeto artístico ou os artefatos culturais. Assim, para os Estudos culturais ocorre uma extensão do significado de cultura, antes exclusivo aos artefatos, para práticas vividas, rompendo com a tradicional concepção de cultura como algo exclusivo de almas selecionadas e refinadas. Nessa visão, a cultura é produção de sentido e não consumo pré-estabelecido de bens culturais

Nessa perspectiva, a cultura popular e a cultura de massa atingem uma legitimidade, passando para um espaço de produção de sentido e intervenção na sociedade. Assim os Estudos Culturais passaram a enfatizar o outro da cultura tradicional, erudita e elitizada: a cultura popular e cultura de massas.

Entretanto, os Estudos culturais criados na Inglaterra se modificaram e se internacionalizaram e tal transformação não alterou o modelo de estudar a alteridade que deixou de ser exclusivamente as culturas de massa e popular, para examinar as práticas culturais de grupos considerados o outro no mundo ocidental. Com esse objetivo, a partir dos anos 70 e 80, os estudos culturais se internacionalizou e suas pesquisas se direcionaram à problemática da dominação, indo ao encontro dos estudos feministas e da crítica cultural francesa ( M. Foucault, Julia Kristeva, Guy Debord e outros), depois acrescendo as questões de raça e etnia. Simultaneamente, a temática da recepção e consumo midiático continua sendo um campo forte durante esse período.

Lembrando que o desenvolvimento da teoria da leitura de G. Schwab se remete aos anos 90, é possível afirmar que essa teoria é fortemente influenciada pelos desdobramentos dos Estudos Culturais nesse contexto. Nessa década, encontra-se, entre outras, os seguintes temáticas: as leituras negociadas e a liberdade individual dos receptores e a questão das subjetividades e identidades.

A teoria da leitura como contato cultural, devido a sua complexidade e a interdisciplinaridade de seus pressupostos, oferece meios eficientes de compreensão do lugar da experiência literária na nossa contemporaneidade, marcada pelo domínio dos meios eletrônicos de comunicação e pelo caráter multicultural das sociedades atuais. 
Por esse motivo, tal perspectiva teórica é radicalmente atual, pois nos permite criar analises e estudos sobre como a leitura da ficção literária pode produz experiências cognitivas, culturais e sociais nas quais o egocentrismo ou o etnocêntricos são transgredidos. Aqui a leitura de textos literários é entendida por um especial processo de recepção na qual as determinações do sujeito são desfeitas e deslocadas para uma zona de indefinição, onde o Eu coexiste com o Outro.

Assim, é viável construir novos estudos sobre o experimentalismo na linguagem literária e suas relações com a cultura e os meios de comunicação na história recente do ocidente. Simultaneamente, podemos repensar o papel da leitura de literatura na formação escolar de crianças e jovens, visando a potencialidade que esse tipo de arte tem para explorar relações com o alteridade. Ou seja, é preciso, através do ensino da literatura, criar meios para desfazer a construção imaginária que muitas culturais do ocidente produziram para os seus considerados Outros: indígenas, mulheres, homossexuais, crianças, loucos, negros e outros. Em suma, acreditamos que a interação entre Estudos Culturais e Teorias da Recepção, através da teoria criada por G. Schwab, permite uma nova importância aos estudos literários tanto no sentido do avanço científico quanto para sua aplicação social.

\section{Referências}

BHABHA, Homi. O local da cultura. Belo Horizonte: Ed. UFMG, 1998.

BATESON, Gregory. Culture Contact and Schismogenesis. Steps to an Ecology of mind. New York: Ballantine/Random, 1972.

BOHANNAN, Laura. Shakespeare in the bush. Disponível em: http://www.naturalhistorymag.com/picks-from-the-past/12476/shakespeare-in-thebush?page=4. Acesso em: jun 2014 .

ESCOSTEGUY, Ana Carolina D. Uma introdução aos estudos culturais. Revista FAMECOS, Porto Alegre, n. 9, dez. 1998.

FISH, Stanley. Is there a text in this class? The authority of interpretive communities. Cambridge: Harvard UP, 1980.

FOUCAULT, Michel. Microfísica do poder. Organização e tradução de Roberto Machado. Rio de Janeiro: Edições Graal, 1979. 
GADAMER, Hans-Georg. Verdade e método: traços fundamentais de uma hermenêutica filosófica. Tradução de Flávio Paulo Meurer. 3. ed. Petrópolis: Vozes, 1999.

ISER, Wolfgang. $O$ ato da leitura: uma teoria do efeito estético. Rio de Janeiro: Ed. 34, 1996.

O fictício e o imaginário: perspectivas de uma antropologia literária. Rio de Janeiro: Eduerj, 1996.

. Teoria da recepção: reação a uma circunstância história. In: ROCHA, João Cezar de Castro (Org). Teorias da ficção: indagações obra de Wolfgang Iser. Rio de Janeiro: Eduerj, 1999.

JAUSS, Hans Robert. A história da literatura como provocação à teoria literária. Trad. de Sérgio Tellaroli. São Paulo: Ática, 1994.

O prazer estético e as Experiências Fundamentais da Poiesis, Aesthesis e Katharsis. In: LIMA, Luis (org.). A literatura e o leitor - textos de Estética da Recepção. Rio de Janeiro: Paz e Terra, 1979.

MERLEAU-PONTY, Maurice. Fenomenologia da percepção. 2.ed. São Paulo: Martins Fontes, 1999.

SANTIAGO, Silviano. Uma literatura Anfíbia. In: O cosmopolitismo do pobre. Belo Horizonte: Ed UFMG, 2004, , p. 64-73.

Poder e Alegria: A literatura Brasileira pós-64-reflexões. In: Nas Malhas da Letra. São Paulo. Companhia das Letras, 1988, p. 11-23.

SCHWAB, Gabriele. Se ao menos eu não tivesse de manifestar-me: a estética da negatividade de Wolgang Iser. In: ROCHA, João Cezar de Castro (Org). Teoria da ficção: indagações à obra de Wolfgang Iser. Rio de Janeiro: EdUERJ, 1999.

The mirror and the Killer-Queen: Otherness in literary language. Bloomington: Indiana University Press, 1996.

Recebido em junho de 2014.

Aceito em outubro de 2014. 